Relations industrielles

Industrial Relations

\title{
La protection des fonds et autres biens syndicaux. Publication du Bureau international du travail, Genève, 1960, 212 pp.
}

\section{Gérard Dion}

Volume 15, numéro 4, octobre 1960

URI : https://id.erudit.org/iderudit/1021954ar

DOI : https://doi.org/10.7202/1021954ar

Aller au sommaire du numéro

Éditeur(s)

Département des relations industrielles de l'Université Laval

ISSN

0034-379X (imprimé)

1703-8138 (numérique)

Découvrir la revue

Citer ce compte rendu

Dion, G. (1960). Compte rendu de [La protection des fonds et autres biens syndicaux. Publication du Bureau international du travail, Genève, 1960, 212 pp.] Relations industrielles / Industrial Relations, 15(4), 516-517.

https://doi.org/10.7202/1021954ar

Tous droits réservés @ Département des relations industrielles de l’Université Laval, 1960
Ce document est protégé par la loi sur le droit d'auteur. L'utilisation des services d'Érudit (y compris la reproduction) est assujettie à sa politique d'utilisation que vous pouvez consulter en ligne.

https://apropos.erudit.org/fr/usagers/politique-dutilisation/ 
Yintensité de l'apprentissage des nouvelles tâches dépendra: 1) du fait que le travailleur est placé dans un milieu où il jouit d'une certaine sécurité et est entouré de gens amicaux et sympathiques; 2) du fait que ses efforts sont sanctionnés par des récompenses ou des punitions importantes dans son système de valeurs. L'auteur conclut ce chapitre par la remarque suivante: (p. 56).

«When we look at industrialization from the view point just offered, it is not surprising that newly industrialized workers usually have a low productivity qualitatively and quantitatively. For employers rarely concern themselves with providing favorable conditions for industrializating their employees. »

En fait, l'auteur va même jusqu'à affirmer que si une entreprise a des travailleurs inadéquats et inefficaces, c'est exclusivement dû 1) à l'ignorance de la part de la direction des coutumes (valeurs et comportements) de ces travailleurs, 2) à l'incapacité de la part de la direction de tenir compte avec objectivité et imagination de ces coutumes.

Ainsi, la direction, pour améliorer le fonctionnement de son organisation, doit non seulement tenir compte des exigences rationnelles venant du côté physique (Taylorisme) ou venant du côté psychologique et social de la vie des travailleurs en usine (relations humaines). Il doit aussi (sinon plus) tenir compte de la culture globale des travailleurs et de la relation entre cette culture et la culture industrielle qu'il veut promouvoir. D'où nécessité de la recherche sociologique et anthropologique pour l'industrie. William $\mathrm{F}$. Whyte insistait déjà sur cette idée dans Man and Organization.

Par ailleurs, «l'industrialisme 》 étant une innovation fondamentale qui produit une acculturation profonde, une désorganisation de la culture traditionnelle et un ajustement social pathologique, ceux qui veulent l'introduire dans une nouvelle région ont un conflit de valeurs à résoudre. En effet, on doit choisir entre le bien-être de la population affectée et la rapidité de l'industrialisation. Si on accorde plus de valeur au bien-être des travailleurs, l'industrialisation doit être lente. Si par ailleurs, le rythme doit être rapide, il faut reconnaitre qu'on sacrifiera une génération sinon deux avant qu'il ne s'établisse une certaine réadaptation de la culture à cette innovation forcée.

En dépit de certaines faiblesses que l'auteur reconnait lui-même, le modèle de Slotkin nous semble très fructueux, non seulement pour l'étude des sociétés «primitives 》 mais même pour une société comme la nôtre. Il y aurait cependant avantage à étendre ce modèle pour qu'il couvre non seulement le problème de l'adaptation du travailleur à l'usine mais aussi celui de l'adaptation plus générale de la culture traditionnelle à la culture industrielle. En particulier, il faudrait tenir compte davantage du fait que l'industrialisation entraîne l'introduction dans la société d'un très grand nombre de coutumes et de valeurs qui sont comme telles extrinsèques à l'usine. En ce sens, l'auteur a peut-être tort de restreindre le concept d'industrialisation à l'introduction de «l'industrialisme * tel qu'il le définit. Un autre point qu'il serait important d'éclaircir théoriquement, du moins dans le cas d'une société comme la nôtre, c'est la motivation qui pousse le travailleur rural vers l'usine plutôt que vers les services, vers telle ville industrielle plutôt que vers telle autre, etc. Ces questions sont soulevées indirectement par le modèle de Slotkin, et on peut entrevoir que le modèle pourrait être étendu pour y répondre de façon plus systématique.

\section{GÉrald Fortin}

\section{La protection des fonds et autres biens} syndicaux. Publication du Bureau international du travail, Genève, 1960, $212 \mathrm{pp}$.

Comment assurer une saine gestion des fonds syndicaux, les protéger contre une utilisation illicite et, en même temps, sauvegarder la liberté d'action syndicale contre une ingérence de la part de l'Etat? Question d'une brûlante actualité dans notre pays, comme à l'échelle mondiale. D'un côté, certains voudraient tout règler par voie de législation, et, à l'autre extrême, on se refuse à toute action gouvernementale. Le Conseil d'administration du Bureau international du travail a été saisi de cette question et a chargé un comité de mener une enquête sur les pratiques en vigueur dans les pays-membres. C'est le résultat de cette enquête qui est l'objet de cet ouvrage. 
Le premier chapitre est consacré aux normes internationales existantes et le dernier contient les conclusions générales qui se dégagent de l'étude. Le corps de louvrage, divisé en huit chapitres, examine la législation et la pratique en vigueur et en particulier les questions suivantes: sources des fonds et des biens syndicaux; fins auxquelles ces fonds et biens peuvent être affectés; administration interne; mesures volontaires permettant ou encourageant une gestion satisfaisante; surveillance de l'administration financière des syndicats pour les pouvoirs publics; sanctions applicables en cas d'utilisation illicite des fonds syndicaux et en cas de non-observation des prescriptions légales; dévolution des biens syndicaux en cas de liquidation ou de dissolution des syndicats

Deux annexes complètent l'étude. Le premier comprend les références aux lois et règlements cités; l'autre fournit une liste des principaux ouvrages à consulter.

Au cours de leur enquête, les rapporteurs ont observé que l'on peut constater une différence assez nette entre les deux grands groupes dans lesquels se classent les mouvements syndicaux du monde, différence qui s'explique par le degré de développement de leur pays respectif, indépendamment de toute considération idéologique. D'une part, lorsque le syndicalisme a atteint un degré de maturité, «même si les dispositions législatives sont différentes, les syndicats ont prouvé qu'ils avaient l'expérience nécessaire pour élaborer à leur gré des règles adéquates pour l'administration de leurs ressources et pour en assurer effectivement le respect ». Par ailleurs, il n'en va pas ainsi dans les pays où l'industrialisation est récente et les syndicats inexpérimentés. Comment alors aider ces syndicats à atteindre un degré d'évolution analogue à celui des syndicats existant de longue date? Ils ne peuvent pas se permettre de se développer aussi lentement que les grands mouvements syndicalistes du XIXe siècle. Les rapporteurs suggèrent alors une aide technique, une assistance qui peut leur venir soit des syndicats plus anciens, des organisations internationales des travailleurs et de l'Organisation internationale du travail elle-même.

Une conclusion particulière se rapportant à l'utilisation des fonds pour Pac- tion politique est très intéressante: « Lorsque les syndicats, conformément à la décision de leurs membres, consacrent une partie de leurs fonds à des activités politiques, les statuts devraient disposer que ces fonds seront versés à un compte spécial, distinct des comptes généraux du syndicat, et que les membres qui ne désirent pas contribuer au fonds politique peuvent s'abstenir de le faire tout en restant membres de plein droit et sans être désavantagés de ce fait $»$.

Quant à la question si délicate de la surveillance de la gestion financière par les pouvoirs publics, les conclusions sont très sages et très prudentes: \&La surveillance exercée sur l'administration des fonds généraux du syndicat par les pouvoirs publics ne devrait pas dépasser normalement le cadre des mesures nécessaires pour contrôler si le syndicat respecte les dispositions législatives expresses, par exemple s'il présente des relevés financiers annuels, et elle ne devrait en aucun cas porter atteinte au droit que l'on reconnaît généralement aux syndicats d'établir leurs statuts et leurs règlements intérieurs, d'élire leurs représentants en toute liberté et d'organiser la gestion de leur activité... Lorsque des sanctions peuvent être infligées à un syndicat qui utilise ses ressources à des fins illicites ou contrevient d'une autre façon aux dispositions législatives relatives à la gestion des biens syndicaux, ces sanctions, à l'exception de la révocation de l'enregistrement, devraient être infligées exćlusivement par les tribunaux, en conformité de la procédure judiciaire régulière, et non par la voie administrative, les syndicats devraient avoir le droit d'interjeter appel devant les tribunaux de la révocation de l'enregistrement $\$$.

Alors qu'en certains milieux, on exerce des pressions sur l'Etat pour accroître les mesures législatives de façon à règlementer davantage l'action syndicale, avant de faire quoi que ce soit, il serait très utile de connaître l'expérience des autres pays contenue dans cet ouvrage et les conclusions des rapporteurs.

\section{GÉRARD Dion}

The Japanese Factory: Aspects of It: Social Organization. By James C. Abegglen. Glencoe, Ill.: The Free Press, 1958.155 pp. $\$ 3.50$. 